\title{
A Young Journal with a Big Heart
}

\author{
Yousef Mohamed Abdulrazzaq \\ Emeritus Professor of Paediatrics and Neonatology, College of Medicine and Health Sciences, \\ UAE University, AI Ain, UAE
}

The United Arab Emirates have a dynamic research sector, which has been emphasised in the recently released 5-year and 30-year plans. However, strangely it lacks an avenue through which the results of medical research could be published. Of course, there are medical journals published in the country, but these are few and do not provide sufficient publication space for the researchers in this country. Dubai Medical Journal [1], based on the premises of Dubai Health Authority, was launched in 2018 to fill this gap. The aim was to provide a venue for the dissemination of research data not only from the UAE, but also from other countries in the world. The object was to create a truly international journal catering to all researchers and acting as an important resource for all medical practitioners worldwide.

The science of medicine, like any other science, always strives to improve itself. New knowledge is continuously being created, and this evolving knowledge needs to be documented. Medical journals are the instruments that drive knowledge. Many physicians depend on a medical journal to inform them of a new treatment modality. For the journals, editors and the peer reviewers are powerful tools that ensure the integrity of the scientists and of their published work. We believe that published research should reach all physicians in a timely manner as far as possible and with no cost. Dubai Medical Journal is available free and is planned to be a high-quality source of information that holds true to these principles and is globally accessible.
C 2021 The Author(s)

Published by S. Karger AG, Basel

This is an Open Access article licensed under the Creative Commons Attribution-NonCommercial-4.0 International License (CC BY-NC) (http://www.karger.com/Services/OpenAccessLicense), applicable to the online version of the article only. Usage and distribution for commercial purposes requires written permission.
The birth of a journal does not happen without labour pains, especially in the beginning, and takes time in establishing itself. I think we have successfully ridden the initial bumps, and the Journal is now known in the country and beyond, judging from the work submitted to the Journal. But recognition alone is not sufficient, and success is measured by the quality of the articles submitted to the Journal. If we were to truly create a quality, authoritative internationally respected journal, the Journal needed to be indexed in well-known international indexes. This would help increase the visibility and attract more researchers to publish in the Journal. It is therefore a matter of pride to announce the indexing of the Journal in the Web of Science [2] and EMBASE [3]. This will hopefully ensure accessibility to a wider audience.

\section{Conflict of Interest Statement}

There is no conflict of interest to declare.

References

1 Dubai Medical Journal [cited June 2021]. Available from: http://www.karger.com/dmj.

2 Web of Science [cited June 2021]. Available from: https://mjl.clarivate.com/search-results? issn $=2571-726 \mathrm{X}$.

3 Embase [cited June 2021]. Available from: https://www.embase.com/.
Correspondence to:

Yousef Mohamed Abdulrazzaq, yousef@uaeu.ac.ae 